Article

\title{
Evaluation of Bead Geometry for Aluminum Parts Fabricated Using Additive Manufacturing-Based Wire-Arc Welding
}

\author{
Hee-keun Lee ${ }^{1}{ }^{1}$, Jisun Kim ${ }^{2, *}$, Changmin Pyo $^{2}$ and Jaewoong Kim ${ }^{2}$ \\ 1 Welding Engineering R\&D Department, Daewoo Shipbuilding Marine Engineering, Geoje 53302, Korea; \\ zetlee@dsme.co.kr \\ 2 Smart Mobility Materials and Components R\&D Group, Korea Institute of Industrial Technology, \\ Gwangju 61012, Korea; changmin@kitech.re.kr (C.P.); kjw0607@kitech.re.kr (J.K.) \\ * Correspondence: kimjisun@kitech.re.kr; Tel.: +82-62-600-6302
}

Received: 25 August 2020; Accepted: 24 September 2020; Published: 26 September 2020

check for updates

\begin{abstract}
The wire arc additive manufacturing (WAAM) process used to manufacture aluminum parts has a number of variables. This study focuses on the effects of the heat input and the current and voltage ratio on the deposition efficiency. The effects of the heat input and current and voltage ratio (V/A) on the bead geometry were analyzed, depending on the cross-sectional geometry of the deposition layers, for nine different deposition conditions. The deposition efficiency was also analyzed by analyzing the cross-sectional geometry of the thin-wall parts made of aluminum. The heat input range was about $2.7 \mathrm{~kJ} / \mathrm{cm}$ to $4.5 \mathrm{~kJ} / \mathrm{cm}$; the higher the heat input, the higher the deposition efficiency. The maximum deposition efficiency achieved in this study was $76 \%$. The current and voltage ratio was used to quantify the portion of voltage $(\mathrm{V})$ in the total heat input $(\mathrm{Q})$, and the effect on the bead geometry was analyzed. As the portion of voltage in the quasi heat input decreased by about $10 \%$, it was found that the deposition efficiency was decreased by $1 \%$ to $3 \%$.
\end{abstract}

Keywords: wire arc additive manufacturing; bead geometry; deposition efficiency; thin-wall parts

\section{Introduction}

Additive manufacturing (AM), also called 3D printing technology, provides 3D geometry by depositing various materials, such as metals, plastics, composites, polymer materials, ceramics etc., by inputting 3D-designed digital geometry information into a manipulator [1-5]. AM technology is largely divided into direct deposition and indirect deposition and can be subdivided into seven different technologies depending on the material [6]. Among these, metal-based AM technology is divided into four types depending on the heat source or processing method, among other factors, and is typically divided into powder bed fusion (PBF) and direct energy deposition (DED) technology, which use a laser heat source and metal powder [7]. Metal AM technology using a metal powder and a laser heat source has been optimized to achieve precise and complex geometry. Many studies in this area have been conducted because the properties of metal can be improved through a combination of metal powders and technology. However, there are limitations to the use of AM technology using high-density energy heat sources and metal powders. Although various geometries can be achieved and the properties of metal materials can be improved by the combination of powders, there are issues such as the deposition speed, product size limitations, high equipment cost and deposition materials (powders). Powder metal 3D printing technology has been applied to parts with a small special ability so far, and its application to large parts is limited [8,9].

Wire arc additive manufacturing (WAAM) technology is similar to the direct energy deposition (DED) method classified by ASTM (American society for testing materials), and this technology 
performs deposition by melting and depositing metal wires using an arc heat source. Generally, WAAM uses gas metal arc welding (GMAW) or gas tungsten arc welding (GTAW) methods, among several welding techniques, to perform continuous metal deposition [10]. WAAM is similar to DED-type 3D printing. The precision of parts is lower because it attaches thin metal wires such as in arc welding.

However, WAAM can use wires that are a half or a third cheaper than metal powder for DED, and there is no need to use expensive laser power sources. In addition, WAAM can deposit large parts faster than powder-type 3D metal printers. Therefore, WAAM is popular in the field of aerospace or shipbuilding where large structures are made [11,12].

WAAM technology is advantageous for the production of complex large parts that cannot be made with the traditional metal powder deposition technology. WAAM technology is being considered as an alternative to the existing casting or machining approaches for metals, which come with a high material loss. Recently, interest in WAAM technology in industries has been increasing, and research on metal deposition using existing commercial welding technology has continued [13-16].

The deposition uniformity of the WAAM process can reduce the material loss that happens during post-processing. While deposition using a general powder provides a stable surface roughness, WAAM has a very rough surface because a single bead geometry is made by melting and depositing a typical size of a minimum $\varnothing 0.8 \mathrm{~mm}$ to a maximum $\varnothing 4.3 \mathrm{~mm}$ wire. Martina et al. [17] explained the use of the deposition volume to assess bead roughness and investigated the efficiency of various welding techniques and conditions.

Köhler et al. [18] continuously stacked aluminum wires using WAAM and observed the changes in bead shapes and structures according to the interlayer temperature. As the wire feed and welding speed increased, the layer height decreased and the wall width increased. Furthermore, the higher the temperature was between passes, the greater the width and height of the aluminum walls were.

Fang et al. [19] compared the mechanical properties of aluminum-laminated parts according to the arc mode of a cold metal transfer (CMT) welder. It was reported that the mechanical properties differed due to the change of the arc mode under the same current and voltage conditions.

Zhang et al. and Xiong et al. $[20,21]$ performed a study to modify the geometry of a single bead to increase efficiency during continuous deposition. Their study compared models of a parabola, cosine and arc to select the most optimized bead profile to represent a single bead shape and investigated how to smooth the surface condition of the deposited material. In addition, they investigated how to measure the bead height in real time during continuous deposition and improve the deposition efficiency by changing the welding conditions in real time based on the measured height.

In this study, basic experiments were performed to produce aluminum parts using WAAM, and the geometry of the deposition layers depending on welding conditions was observed. The effects of the heat input and current and voltage ratio on the bead geometry for nine different welding conditions (depositing conditions) were analyzed, and the depositing efficiency was also analyzed by analyzing the cross-sectional geometry of thin-wall parts made of aluminum.

\section{Experiment Method}

\subsection{Experimental Systems}

Figure 1 shows the combination of the robot system and MIG welding machine used in the welding experiment. A Fronius CMT welding machine was used, and a Motorman HP20D six-axis robot was employed as the motion provisioning unit. The accuracy of the motion system was $0.06 \mathrm{~mm}$. The jig used in the welding experiment was designed to minimize the deformation of the substrate. To measure the temperature of the base material, a k-type thermocouple (GL240 model from GRAPHTEC, Irvine, CA, USA) was inserted into the $2 \mathrm{~mm}$ depth hole at the bottom of the substrate to measure the temperature of the base material, which was $5 \mathrm{~mm}$ in depth from the substrate surface. The sampling data rate for the temperature measurement was four times per second (250 ms). 


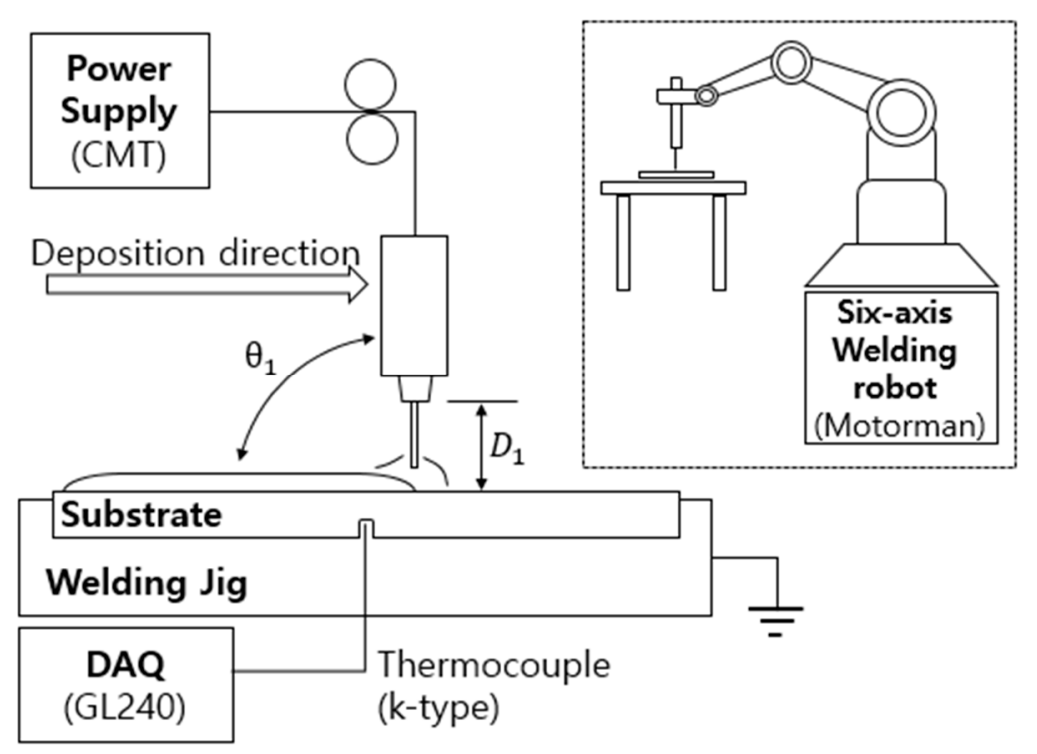

Figure 1. Schematic diagram of MIG based additive manufacturing (AM) systems for Al alloy. CMT: cold metal transfer.

This study consisted of two experiments undertaken to observe single-bead and multi-bead geometry. For the welding of a single bead, a working angle $(\theta 1)$ of $90^{\circ}$ and a contact tip to workpiece distance (CTWD, D1) of $15 \mathrm{~mm}$ were used.

For the experiments, 7075 series aluminum with a size of $250 \mathrm{~mm}(\mathrm{~L}) \times 75 \mathrm{~mm}(\mathrm{~W}) \times 7 \mathrm{~mm}(\mathrm{H})$ was used as the substrate. A $1.2 \mathrm{~mm}$ diameter ER5356 aluminum alloy wire was used as the deposition material. Ar (99.99\%) was applied as a shielding gas for the welding torch, with a flow rate of $18 \mathrm{~L} / \mathrm{min}$.

\subsection{MIG Welding Parameters for Deposition of Al Alloy}

In the first experiment, the changes of the bead geometry were observed when a single bead was continuously deposited in nine different conditions. In the CMT welding process, the magnitude of the current $(\mathrm{A})$ and voltage $(\mathrm{V})$ was determined according to the feed amount of the welding wire. In addition, the magnitude of the voltage could be adjusted by finely adjusting the length of the arc. Six conditions for welding were selected through a preliminary experiment, shown as conditions 1 to 6 in Table 1.These were conditions in which the heat input was sequentially increased from $2.7 \mathrm{~kJ} / \mathrm{cm}$ to $4.46 \mathrm{~kJ} / \mathrm{cm}$. Conditions 1 to 6 in Table 1 were the conditions used to observe the difference in bead shapes caused by the difference in heat inputs. In addition, three additional conditions were selected to observe the bead shape changes according to the ratio of current and voltage. The added three conditions are shown in Table 1 conditions 7 to 9 as conditions 1, 3 and 6, and each condition represents an experimental condition in which the current voltage ratio was lowered.

The welding conditions from 1 to 6 were determined by increasing the wire feed rate from $5 \mathrm{~m} / \mathrm{min}$ to $7.5 \mathrm{~m} / \mathrm{min}$ at $0.5 \mathrm{~m} / \mathrm{min}$ intervals; conditions 7,8 and 9 had a lower voltage than conditions 1,3 and 6 , as shown in Table 1 . The welding speed was fixed at $30 \mathrm{~cm} / \mathrm{min}$ to consider only the influence of current and voltage. A high ratio of current and voltage means that the ratio of the voltage involved in the total heat input increased. In terms of the heat input, the voltage and current were different. If the heat input remains the same, the same beads must be formed; however, the bead shapes were actually different. The reason for the difference in bead shapes was that the ratios of the voltage or current to the total amount of heat input were different. The differences between the heat inputs and the current and voltage ratios affected the geometry of a single beadm and the difference between the single bead geometry accumulated as the number of deposition increased, resulting in a difference in the geometry of thin-wall parts. 
Table 1. Parameters of single-layer and multi-layer deposition.

\begin{tabular}{ccccccc}
\hline $\begin{array}{c}\text { Weld ID. } \\
\text { No. }\end{array}$ & $\begin{array}{c}\text { Current } \\
\text { (A) }\end{array}$ & $\begin{array}{c}\text { Voltage } \\
\text { (V) }\end{array}$ & $\begin{array}{c}\text { Welding } \\
\text { Speed } \\
(\mathbf{c m} / \mathbf{m i n})\end{array}$ & $\begin{array}{c}\text { Wire Feed } \\
\text { Rate } \\
(\mathbf{m} / \mathbf{m i n})\end{array}$ & $\begin{array}{c}\text { Heat Input } \\
(\mathbf{k J})\end{array}$ & $\begin{array}{c}\text { Current and } \\
\text { Voltage } \\
\text { Ratio (V/A) }\end{array}$ \\
\hline 1 & 80 & 17.1 & 30 & 5 & 2.736 & 0.21 \\
2 & 87 & 17.5 & 30 & 5.5 & 3.045 & 0.20 \\
3 & 92 & 18 & 30 & 6 & 3.312 & 0.20 \\
4 & 102 & 18.3 & 30 & 6.5 & 3.7332 & 0.18 \\
5 & 110 & 18.4 & 30 & 7 & 4.048 & 0.17 \\
6 & 118 & 18.9 & 30 & 7.5 & 4.4604 & 0.16 \\
7 & 83 & 16 & 30 & 5 & 2.656 & 0.19 \\
8 & 95 & 16.5 & 30 & 6 & 3.135 & 0.17 \\
9 & 112 & 17.2 & 30 & 7 & 3.8528 & 0.15 \\
\hline
\end{tabular}

Multi-layer deposition was performed to observe the deposition efficiency according to welding conditions by implementing thin-wall parts. Aluminum thin-wall parts were deposited using a zigzag route for 15 layers, and a total of nine conditions were used as shown in Table 1. The length of the thin-wall parts was $150 \mathrm{~mm}$. Figure 2 shows the thin-wall parts fabricated through 15 consecutive depositions using the same conditions as a single bead.

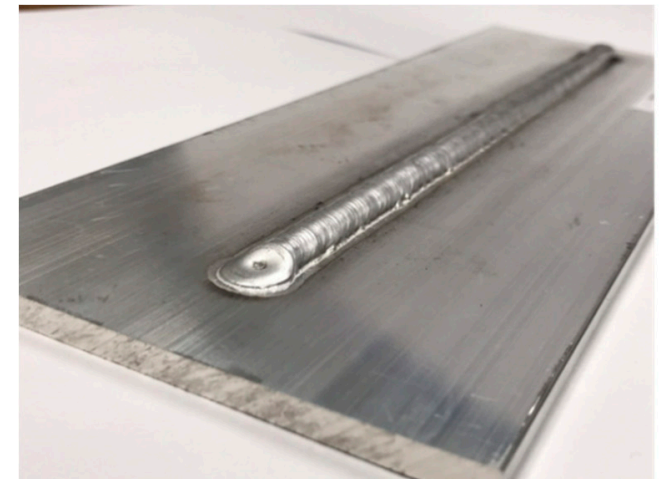

(a) Single bead

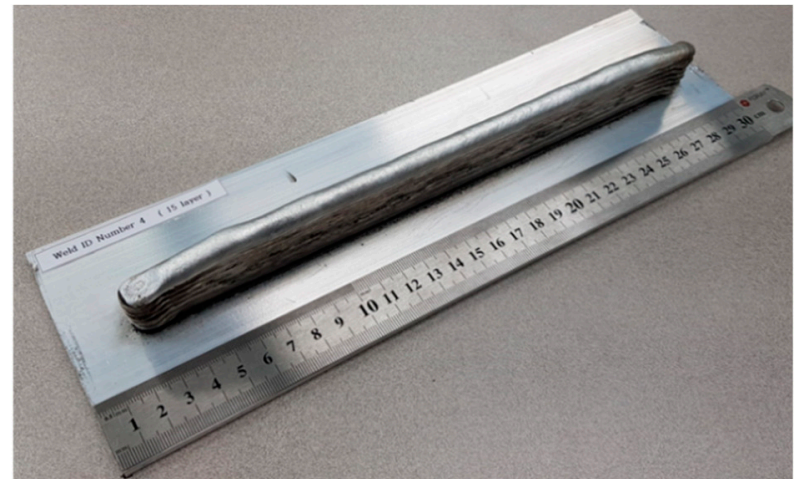

(b) Thin wall parts

Figure 2. Schematic diagram of MIG-based AM systems for Al alloy.

\section{Results and Discussion}

A total of nine conditions were used for the single-bead experiment and to produce the thin-wall parts. To analyze the geometry of the cross-section, the part was cut into the cross section from the center of the test piece. Polishing and etching were performed to closely observe the geometry of the cut section. Figure 3 shows the geometry of a single bead and the cross-sectional geometry of the thin-wall parts made from the continuous deposition of single beads. In Figure 3a-f, the overall heat input can be seen to have increased as the wire feed amount increased sequentially. The wire feed amount and the heat input $(\mathrm{Q})$ had a proportional relationship [22]. In this study, the synergy line of the CMT welding process was used, and the amount of heat input was controlled by controlling the wire supply speed under the conditions provided. In addition, the current and voltage ratio was controlled by finely modifying the arc length. While the heat input per wire feed amount was kept constant at 0.5 to $0.59 \mathrm{~kJ}$, the geometry of the beads was different. The geometry of a single bead affects the geometry of the beads that are deposited continuously; thus, the geometry of a single bead was closely observed to analyze this relationship. Figure 4 shows the results of continuous deposition experiments under the conditions shown in Table 1. It was found that the continuously deposited thin-wall parts had a narrow bead width at the root position, and a wall with a constant thickness was produced as the number of depositions gradually increased. 

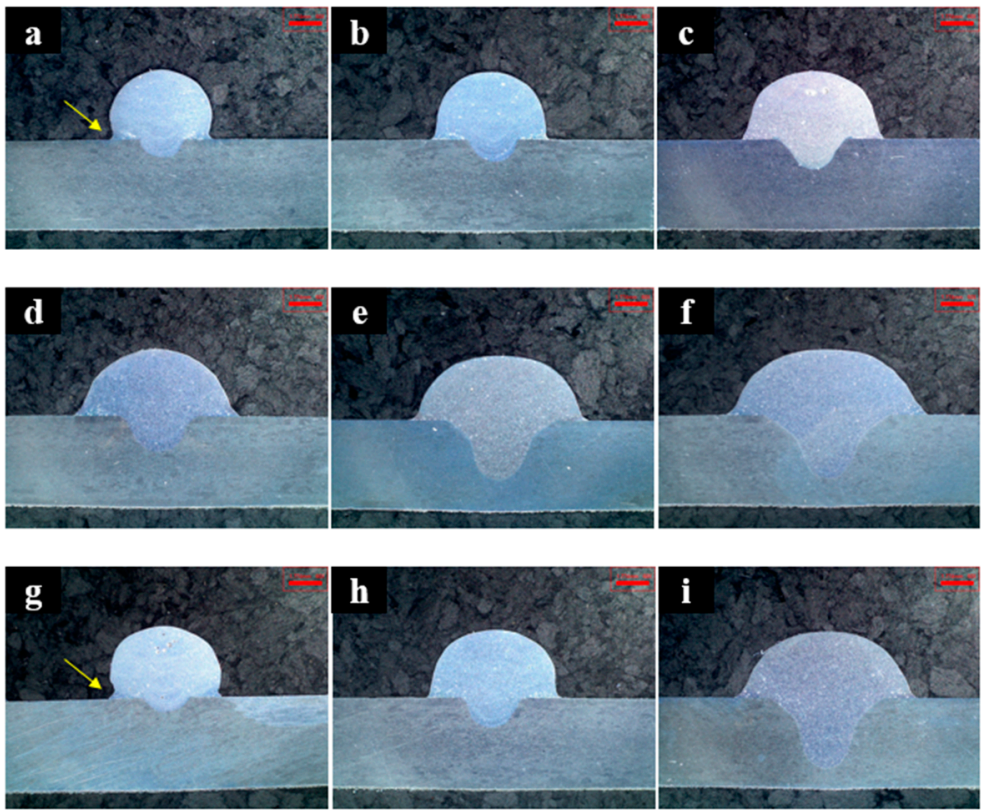

Figure 3. Macro-section images of a single bead according to MIG welding conditions of (a) $80 \mathrm{~A}$, $17.1 \mathrm{~V}$; (b) $87 \mathrm{~A}, 17.5 \mathrm{~V}$; (c) $92 \mathrm{~A}, 18 \mathrm{~V}$; (d) $102 \mathrm{~A}, 18.3 \mathrm{~V}$; (e) $110 \mathrm{~A}, 18.4 \mathrm{~V}$; (f) $118 \mathrm{~A}, 18.9 \mathrm{~V}$; (g) $83 \mathrm{~A}, 16 \mathrm{~V}$; (h) $95 \mathrm{~A}, 16.5 \mathrm{~V}$; (i) $112 \mathrm{~A}, 17.2 \mathrm{~V}$.
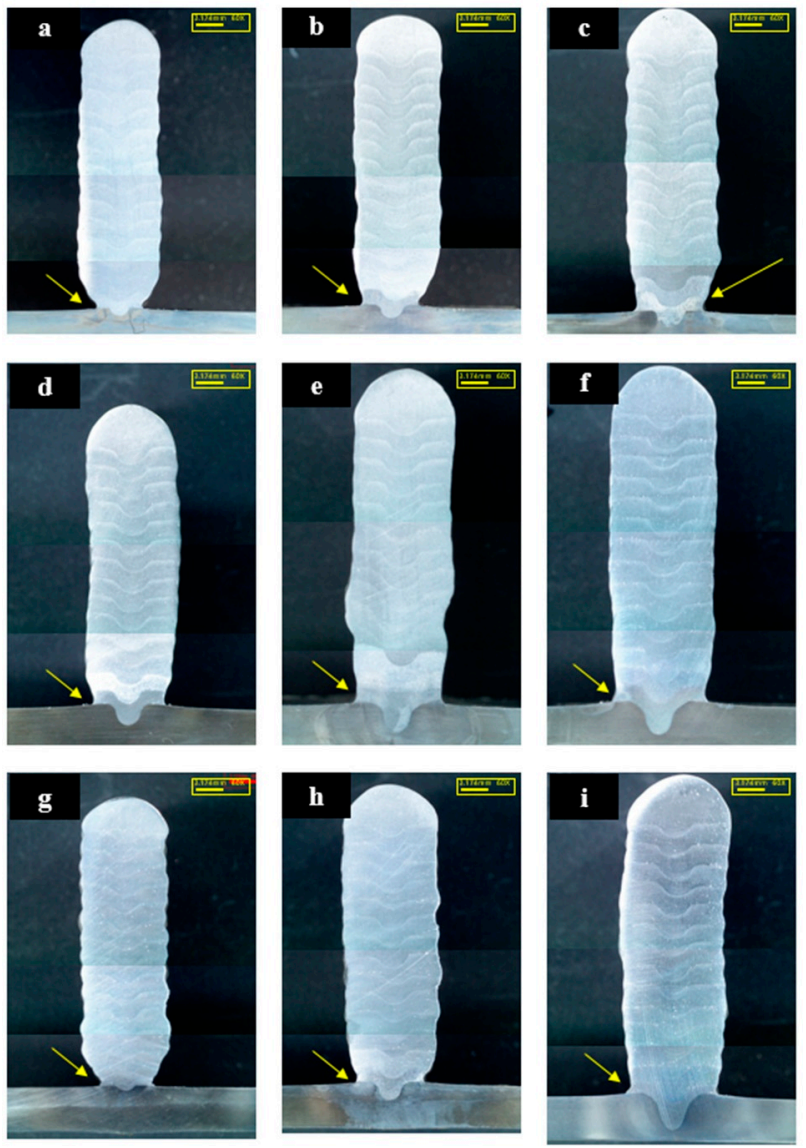

Figure 4. Macro-section images of a multi-layer bead according to MIG welding conditions of (a) $80 \mathrm{~A}$, $17.1 \mathrm{~V}$; (b) $87 \mathrm{~A}, 17.5 \mathrm{~V}$; (c) $92 \mathrm{~A}, 18 \mathrm{~V}$; (d) $102 \mathrm{~A}, 18.3 \mathrm{~V}$; (e) $110 \mathrm{~A}, 18.4 \mathrm{~V}$; (f) $118 \mathrm{~A}, 18.9 \mathrm{~V}$; (g) $83 \mathrm{~A}, 16 \mathrm{~V}$; (h) $95 \mathrm{~A}, 16.5 \mathrm{~V}$; (i) $112 \mathrm{~A}, 17.2 \mathrm{~V}$. 


\subsection{Effect of Heat Input Rate for Single Bead}

To analyze the effect of welding conditions on the geometry of a single bead, the bead width $(\mathrm{mm})$, bead height $(\mathrm{mm})$, contact angle $\left(^{\circ}\right)$, bead radius $(\mathrm{mm})$ and bead circle center position $(\mathrm{mm})$ were measured as shown in Figure 5.

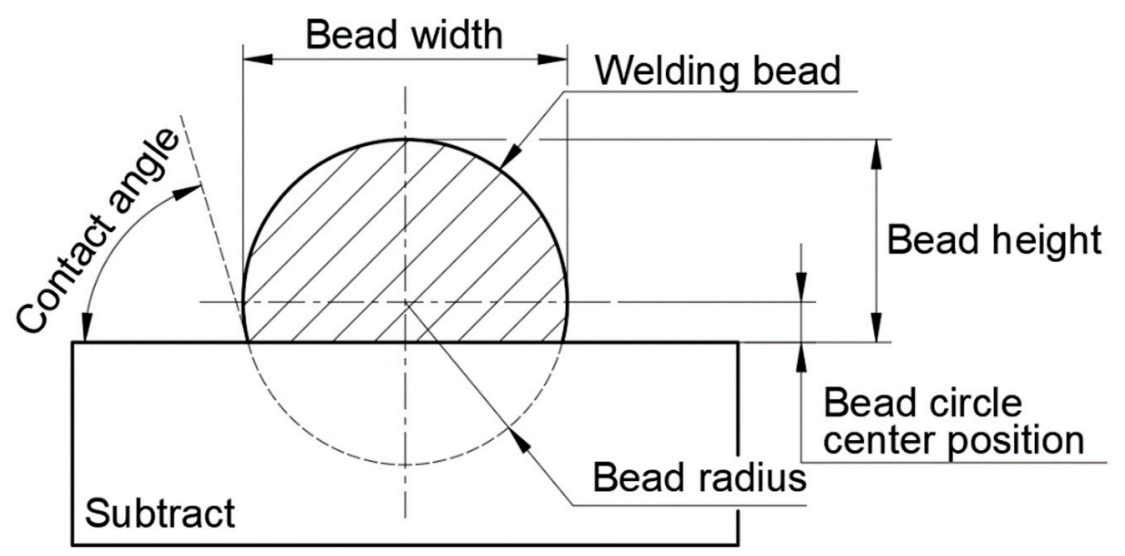

Figure 5. Definition of measurement points on bead cross-section.

For a typical arc heat source, the heat input rate $(\mathrm{Q})$ is calculated by the current $(\mathrm{A})$, the voltage $(\mathrm{V})$ and the welding speed (s) and process efficiency $\left(\eta_{w}\right)$, and the relationship is shown in Equation (1).

$$
\mathrm{Q}=\frac{\mathrm{A} \times \mathrm{V}}{\mathrm{s}} \eta_{w}(\mathrm{~J} / \mathrm{cm})
$$

Measurements of the changes in bead geometry parameters due to changes in the heat input (calculated by Equation (1)) were recorded. Figure 6 is a graphical representation of the bead geometry according to the heat input rate. Curve fitting was performed to clearly analyze the correlation between the heat input and bead shape. The R-square of the bead height for the heat input was 0.51 , and the correlation between the heat input and the bead height was very weak. The R-square of all other output variables was 0.9 or higher, indicating a strong correlation. Figure 6a proves that the heat input and the bead width are proportional; as the heat input increases, the bead width continuously increases. Furthermore, the heat input and the wire feed amount is proportional; increasing the wire feed amount means that the bead size increases, so the bead width also increases. The bead radius increases as the wire feed amount increases. It was observed in our experiment that the amount of welding metal increases as the wire feed amount increases.

However, as shown in Figure 6b, the bead height cannot be easily explained in terms of heat input. No regular change in bead height was observed despite changes in heat input. However, the reason for the change in bead height when the heat input is $2.5 \mathrm{~kJ} / \mathrm{cm}$ is higher than that of $4.5 \mathrm{~kJ} / \mathrm{cm}$ seems to be that the smaller the heat input, the more heat energy is used to melt the wire rather than the base material. One of the pieces of evidence that can explain this is that, as shown in Figure 6e, the lower the heat input, the higher the center of the circle (that may represent a bead) from the substrate surface. When the center is positive, it means that the bead maintains a circular shape as much as possible due to the surface tension; this also means that the mixing portion in the welding metal formed by the melt substrate and wire is very small.

In addition, as shown in Figure $6 c$, it is observed that the smaller the heat input, the smaller the contact angle, and the larger the heat input, the larger the contact angle. It was found that, as the heat input increased, the contact area between the base material and the welding metal increased. 


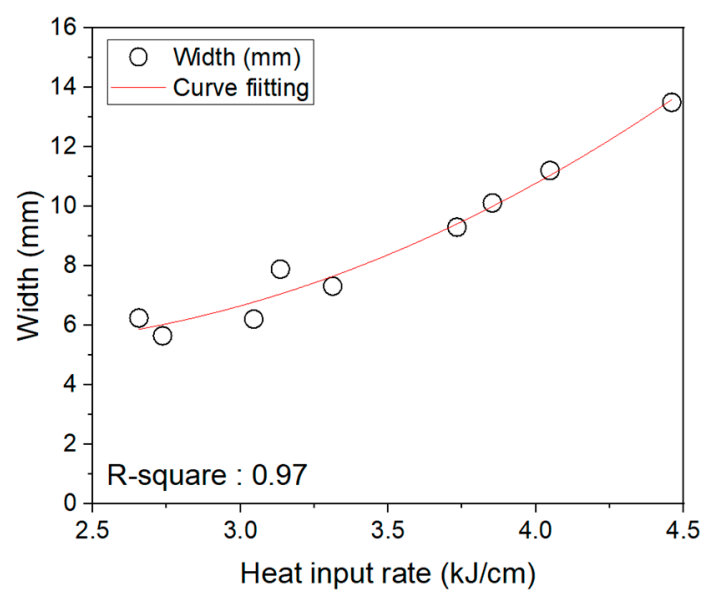

(a)

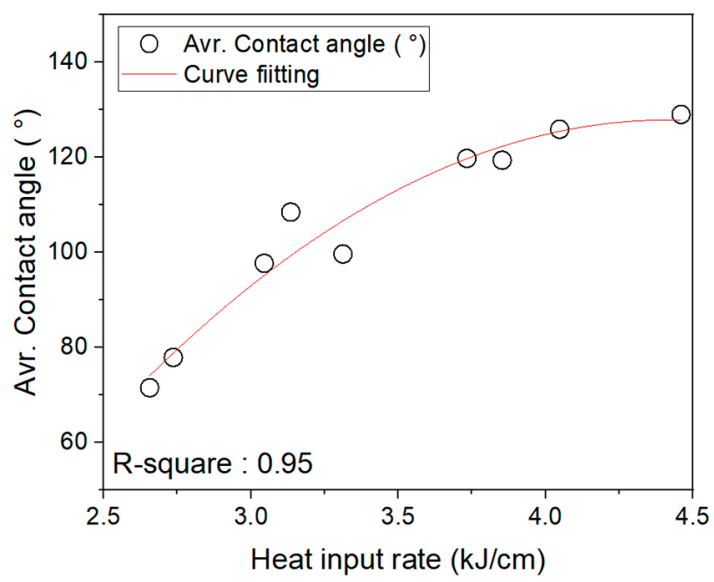

(c)

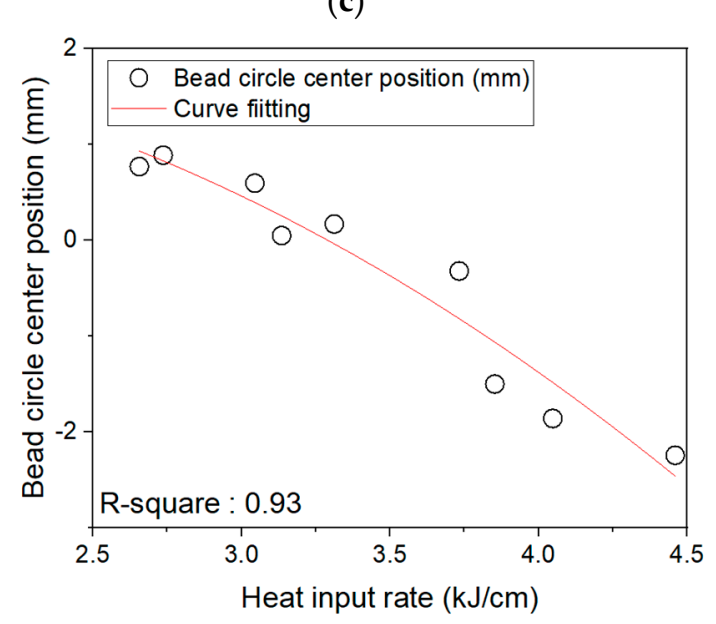

(e)

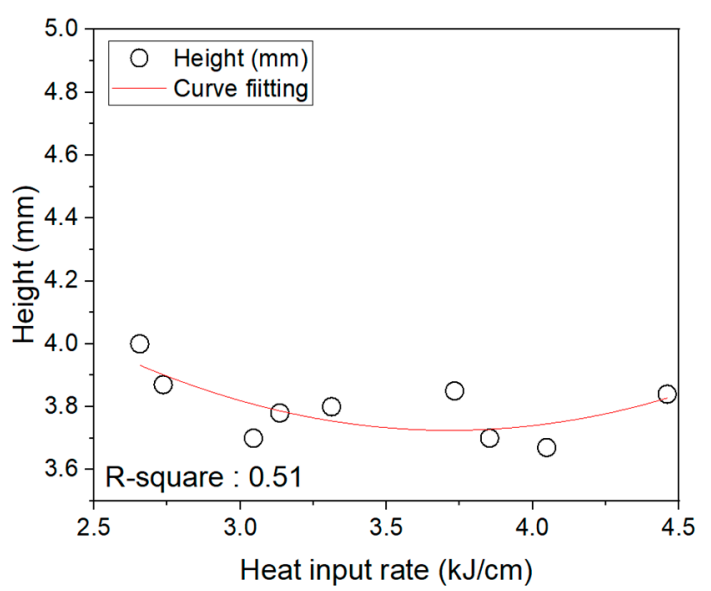

(b)

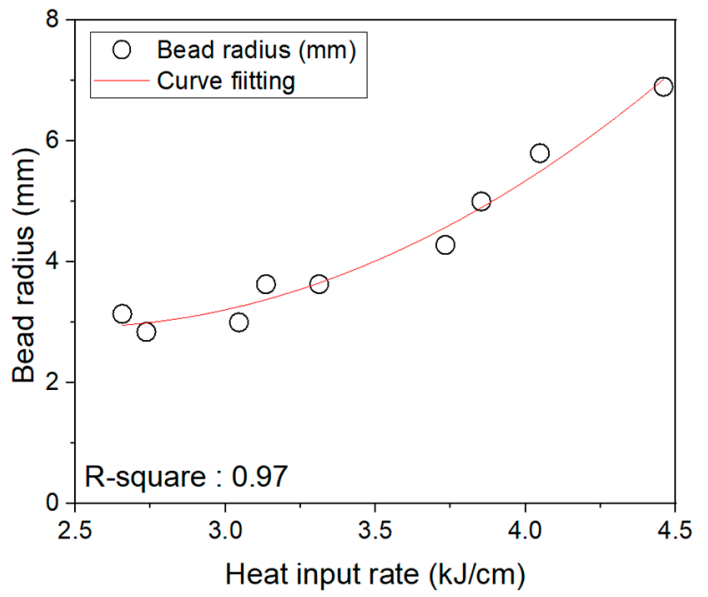

(d)

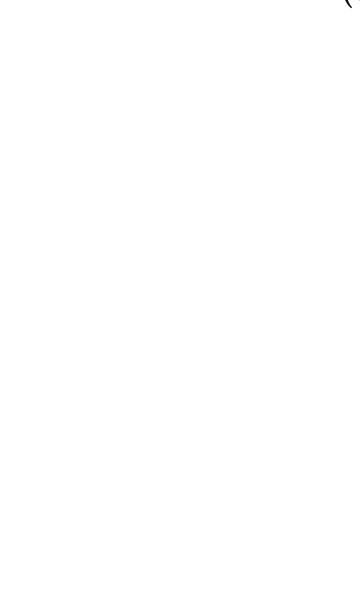

Figure 6. Geometry fluctuation of beads according to heat input rate. (a) Width fluctuation according to heat input rate. (b) Height fluctuation according to heat input rate. (c) Contact angle fluctuation according to heat input rate. (d) Bead radius fluctuation according to heat input rate. (e) Circle center position fluctuation according to heat input rate.

\subsection{Effect of Current and Voltage for Single Bead}

The definition of the current and voltage ratio is shown in Equation (2). As shown in Equation (1), the heat input rate for a typical arc heat source is calculated by the current, voltage and welding speed. 
Here, even under conditions of the same heat input, the ratio of the voltage to the total heat input can be controlled through the precise control of the current and voltage.

In this study, we observed the difference in bead geometry caused by the difference of the current and voltage ratio at similar heat inputs through the precise control of voltage and current. The definition of the current and voltage ratio is as shown in Equation (2).

$$
\text { Current and voltage ratio }=\frac{\mathrm{V}}{\mathrm{A}}
$$

A bead geometry according to the current and voltage ratio calculated by Equation (2) was observed.

Curve fitting was performed to clearly analyze the correlation between the heat input and bead shape, as well as to clearly analyze the correlation between the current and voltage ratio and bead shape. For the current and voltage ratio, the R-square of the bead height is 0.174 , and the correlation between the current and voltage ratio and the bead height is very weak. The R-square of other output variables was about 0.7 or more, which means that there is a correlation.

As shown in Figure 7a, it is observed that the bead width decreased as the current and voltage ratio increased. The same is observed for the contact angle and radius, as shown in Figure 7c,d. In other words, the larger the portion of voltage in the total heat input, the smaller the bead width and the smaller the overall bead size, and the area fused to the base material becomes smaller. As shown in Figure $7 \mathrm{a}, \mathrm{c}, \mathrm{d}$, the opposite pattern appears when the heat input is increased. For the bead height, the difference caused by the change of the current and voltage ratio is very irregular, and so it is difficult to infer any trend. As shown in Figure 7e, the position of the bead center is elevated gradually from the substrate surface as the current and voltage ratio increases. The reason why the bead center is elevated can be explained by the contact angle. As the portion of the voltage in the total heat input increases, the contact angle decreases and the bead geometry becomes closer to a circle. The closer the bead geometry is to a circular geometry, the more the area directly melted with the base material decreases, and so the deposition efficiency decreases.

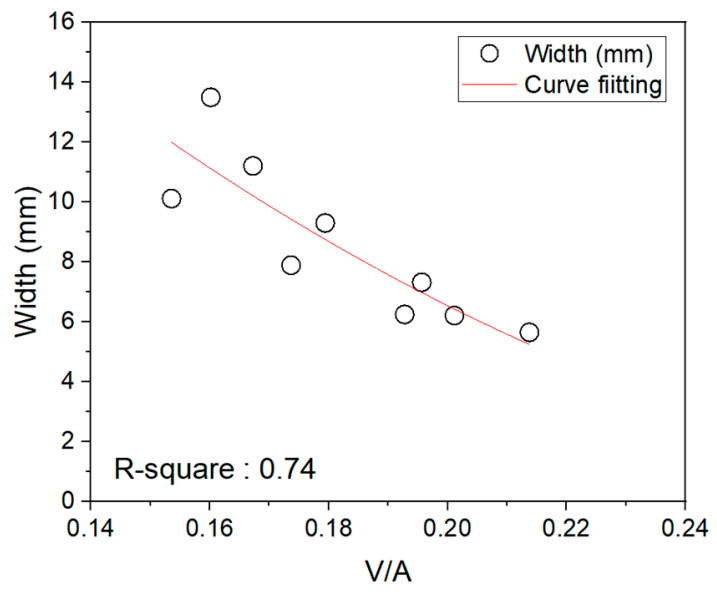

(a)

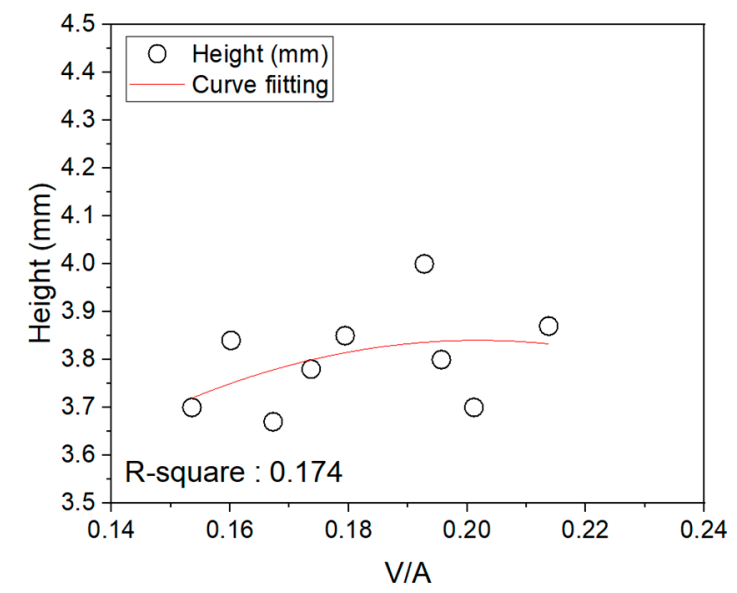

(b)

Figure 7. Cont. 


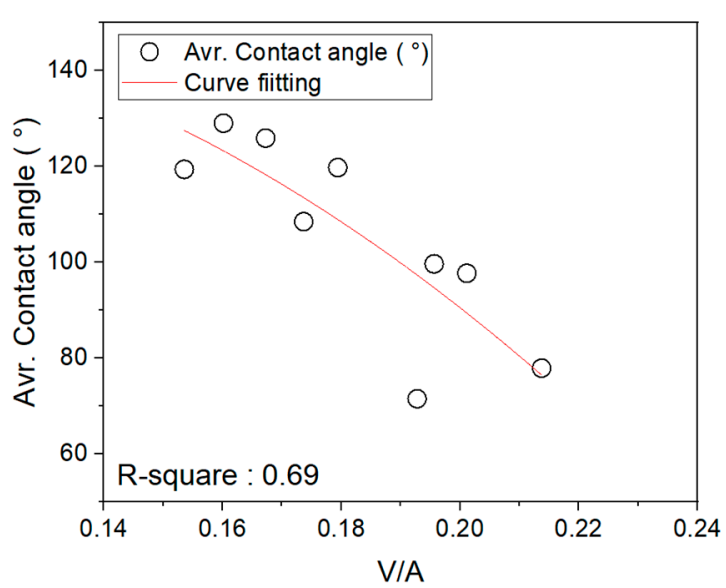

(c)

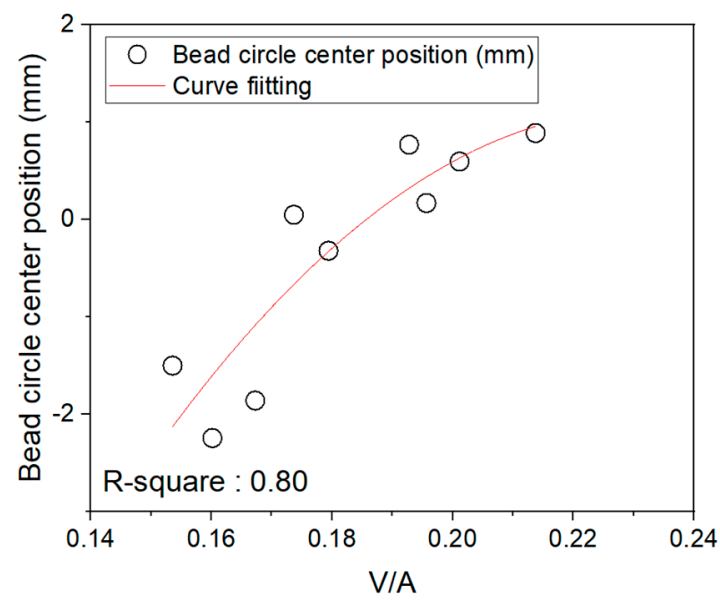

(e)

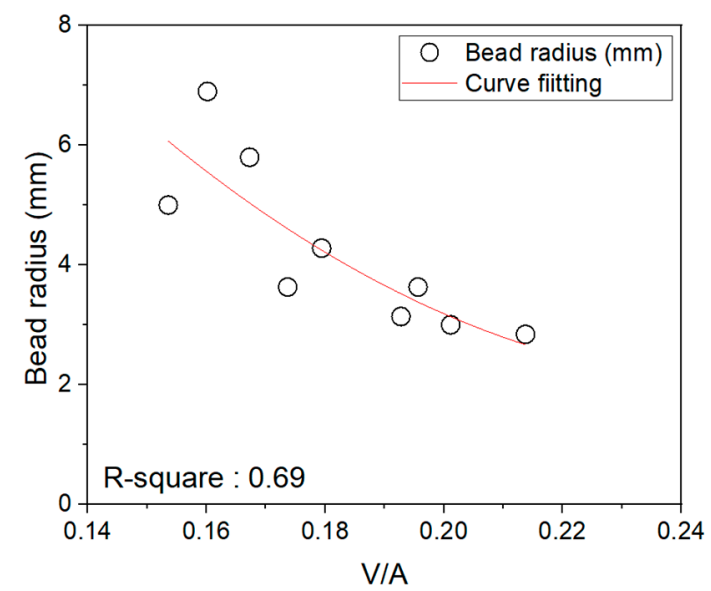

(d)

Figure 7. Geometry fluctuation of beads according to the current and voltage ratio. (a) Current and voltage ratio versus width. (b) Current and voltage ratio versus height. (c) Current and voltage ratio versus contact angle. (d) Current and voltage ratio versus bead radius. (e) Current and voltage ratio versus circle center position.

\section{Effect of Temperature}

In similar heat input conditions, the change of the current and voltage ratio affects the maximum temperature of the base material (substrate). Figure 8 shows the change in temperature of the base material when the total heat input is similar and the current and voltage ratio is different. In Figure $8 \mathrm{a}$, the total heat input is similar at $2.736 \mathrm{~kJ} / \mathrm{cm}$ and $2.656 \mathrm{~kJ} / \mathrm{cm}$, but the temperature of the base material changes due to the difference in the current and voltage ratio. Figure $8 b, c$ shows the temperature change caused by the decrease of the current and voltage ratio under similar heat input conditions. The decrease of the current and voltage ratio decreases the heat input rate delivered to the base material. In other words, as the portion of the voltage in the total heat input increases, the energy delivered to the base material decreases. The difference in energy delivered to the base material causes a difference in bead geometry during continuous deposition and affects the deposition efficiency. 
(a)

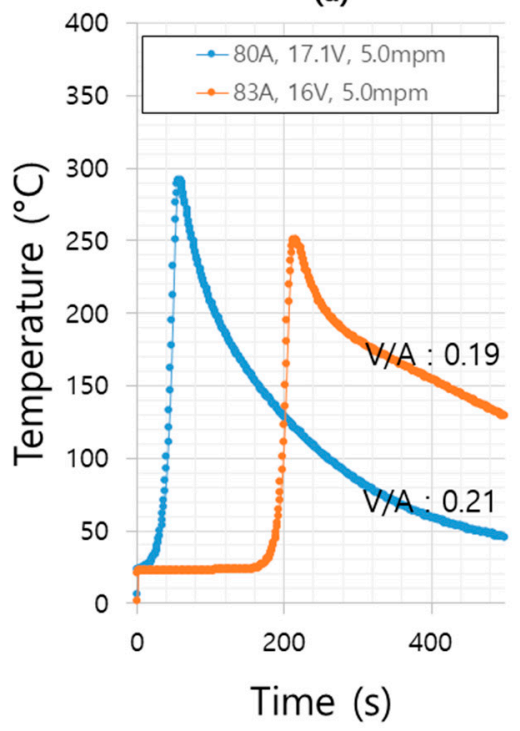

(b)

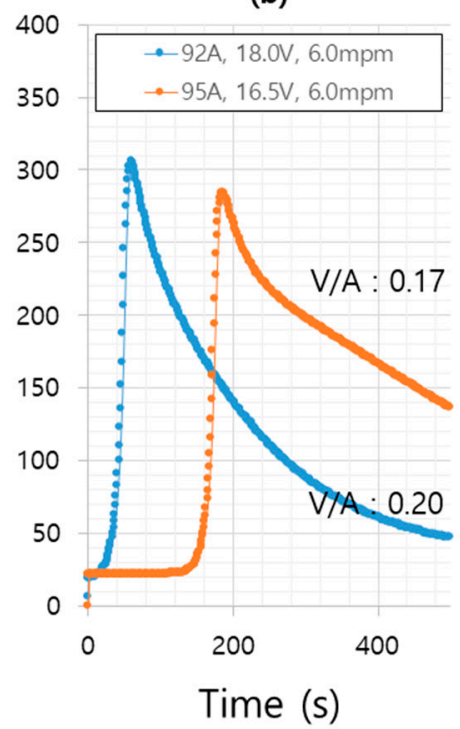

(c)

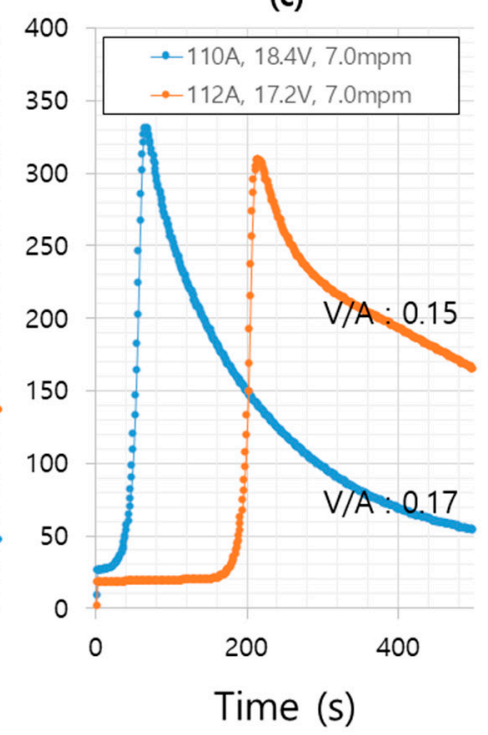

Figure 8. Variation of temperature profile on the substrate according to the current and voltage ratio.

\subsection{Efficiency of Deposition}

It was found that the geometry of a single bead, as described above, changes depending on the welding conditions (heat input, current and voltage ratio), and the geometry of a single bead is related to the efficiency of the continuous deposition. In general, WAAM-based fabrication quickly produces a very rough geometry through the continuous deposition of a single bead, and then achieves the final geometry of a product through cutting. In the traditional subtract process approaches, such as cutting and machining, the productivity is low because of the high material loss when using a bulk material; furthermore, the cutting time is long and the lifecycle of machining tools is short. Therefore, in WAAM technology, a uniform bead geometry is critical to minimize the material loss from the cutting and machining process and to maximize economic efficiency [23-25]. In this study, to evaluate the deposition efficiency of continuously deposited thin-wall parts, the cross section of the deposited material was analyzed as shown in Figure 9.

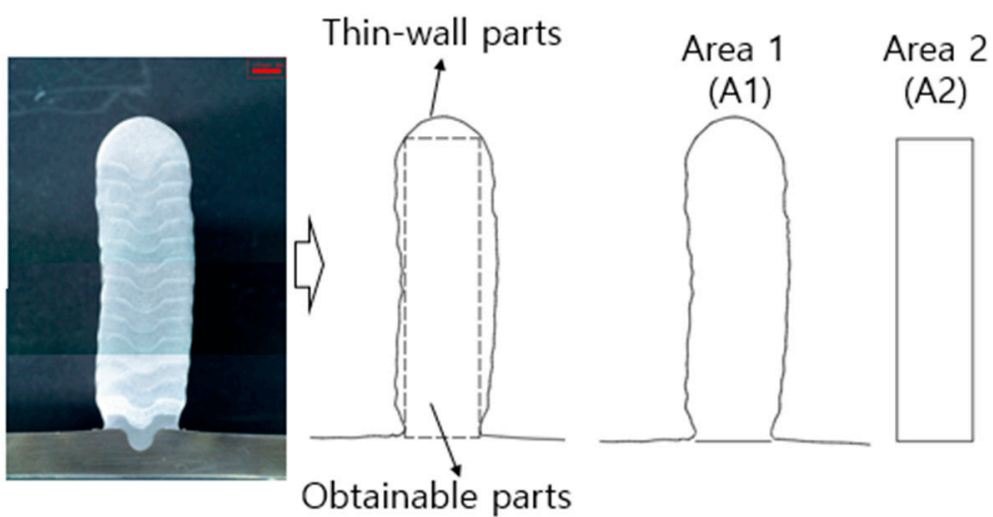

Figure 9. Determining the effective area of thin-wall parts for efficiency calculation.

The deposition efficiency $\left(\eta_{d}\right)$ was determined by Equation (3), where the usable area was divided by the total area; that is, the variable A1 is the cross-section area of the thin-wall parts deposited through WAAM and the variable A2 is the rectangle area obtainable from the deposited thin-wall parts. The cross-sectional profiles of the deposited thin-wall parts were measured using a 3D measuring 
device. The efficiency of deposition was determined by the ratio of the maximum area of the usable square to the total area of the deposited wall, from top to bottom.

$$
\text { Efficiency of deposition }\left(\eta_{d}\right)=\frac{\mathrm{A} 2}{\mathrm{~A} 1}(\%)
$$

\subsection{Comparision of Deposition Efficiency}

Figure 10 shows the results of analyzing the deposition efficiency according to the heat input. The higher the heat input, the higher the deposition efficiency. When the heat input is around $2.5 \mathrm{~kJ} / \mathrm{cm}$, the deposition efficiency is less than $60 \%$. As shown in Figure $4 \mathrm{a}$, the root of the thin-wall parts is found to be very narrow compared to the body. On the other hand, when the heat input is $4.5 \mathrm{~kJ} / \mathrm{cm}$, the deposition efficiency is over $70 \%$ and, as shown in Figure $4 \mathrm{f}$, the root and body parts of the thin-wall parts have almost the same width. When the heat input is high, it is assumed that the heat source of the arc perfectly melts both the base material and the wire, so the bead width and contact angle are both increased, and this leads to increased deposition efficiency.

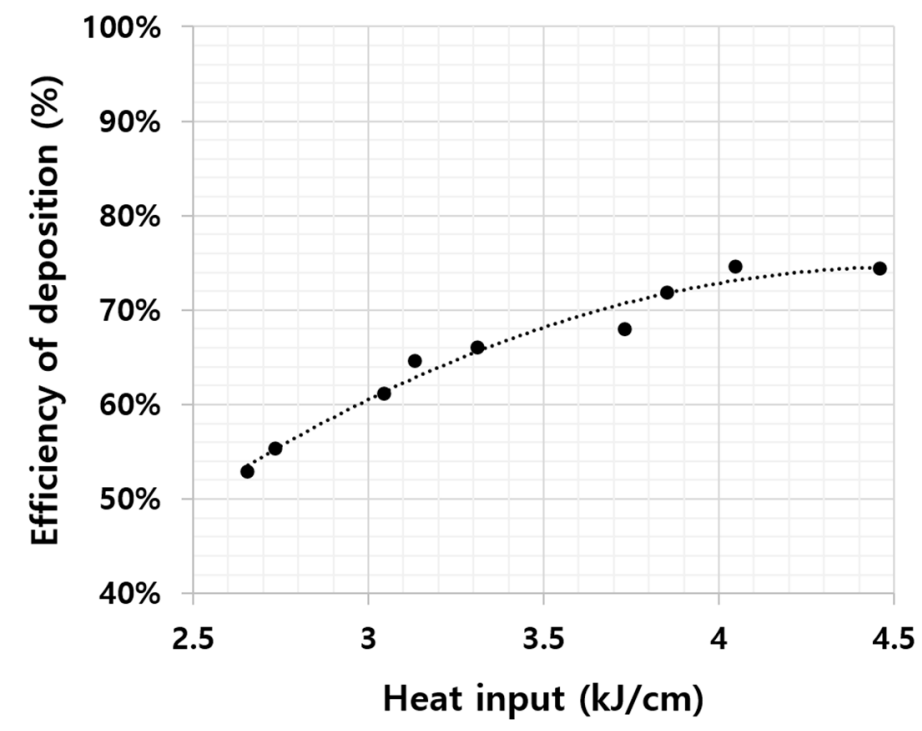

Figure 10. Variation of efficiency of deposition according to heat input $(\mathrm{kJ} / \mathrm{cm})$.

Based on Equation (3), the efficiency produced by the difference of the current and voltage ratio under similar heat inputs is compared. Figure 3 shows three cases of efficiency degradation caused by the difference of the current and voltage ratio under similar heat inputs. The left side of Figure 11 shows that the deposition efficiency decreased by about $2 \%$ when the current and voltage ratio decreased from 0.21 to 0.19 under the same welding conditions of a wire feeding speed at $5.0 \mathrm{~m} / \mathrm{min}$. In addition, the deposition efficiency decreased from $1 \%$ to $3 \%$ as the current and voltage ratio decreased when the wire feed speed was $6 \mathrm{~m} / \mathrm{min}$ or $7 \mathrm{~m} / \mathrm{min}$ each. The reason for the decreased deposition efficiency is assumed to be that the penetration depth and width of the bead decreased as the voltage decreased, and this led to the narrow root of the thin-wall parts. When the root portion of the thin-wall parts becomes narrow, the bottom surface of the square column reaches the maximum length of the root portion, although the bead width increases through continuous deposition and the resulting narrow root portion significantly affects deposition efficiency degradation.

\subsection{Hardness Test Results}

In order to confirm the change in mechanical properties that may occur due to the difference in the current and voltage ratio and heat input, the most easily accessible hardness measurement experiment was performed. The hardness was continuously measured from the bottom of the aluminum 
thin wall to the top of the substrate at $1 \mathrm{~mm}$ intervals. The hardness tests were performed using an HMV-G (Shimadzu, micro Vickers hardness tester, Kyoto, Japan). The experiment was performed by applying an indentation load of $490.3 \mathrm{mN}$ (HV0.05) and an indentation time of $10 \mathrm{~s}$. Figure 12 shows the results of hardness measurement according to different conditions (heat input, current and voltage ratio). The conditions of the maximum and minimum of the heat input and current and voltage ratio were compared. The blue line in Figure 12 shows a current and voltage ratio of 0.21 , and the red line shows a current and voltage ratio of 0.15 . Despite the difference in the current and voltage ratio, the two lines are located at $80 \mathrm{HV}$, and no significant difference is observed. Furthermore, there is no difference due to heat input rate. As a result of the hardness test, it was confirmed that the hardness did not change due to the difference in the heat input and current and voltage ratio in the welding conditions used in this study.

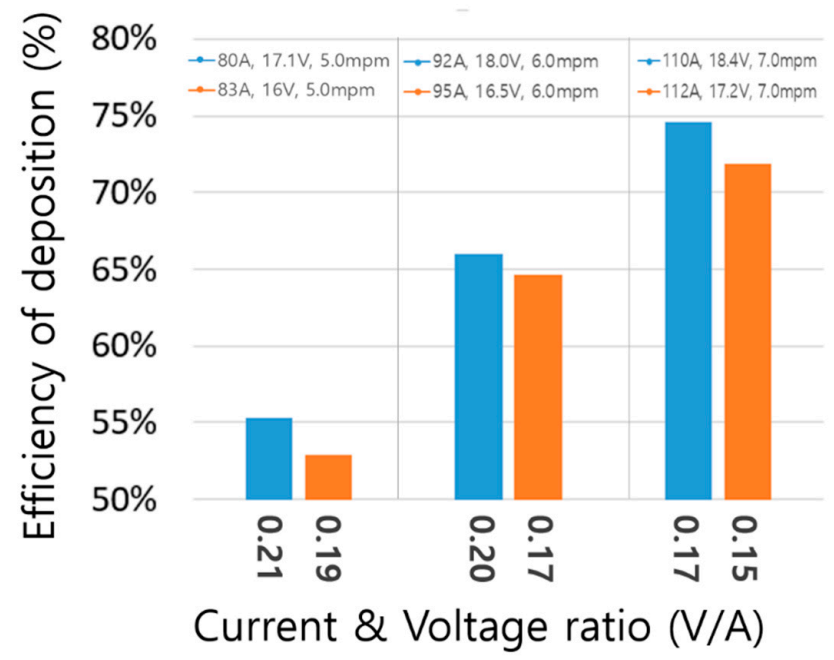

Figure 11. Variation of efficiency of deposition according to the current and voltage ratio.

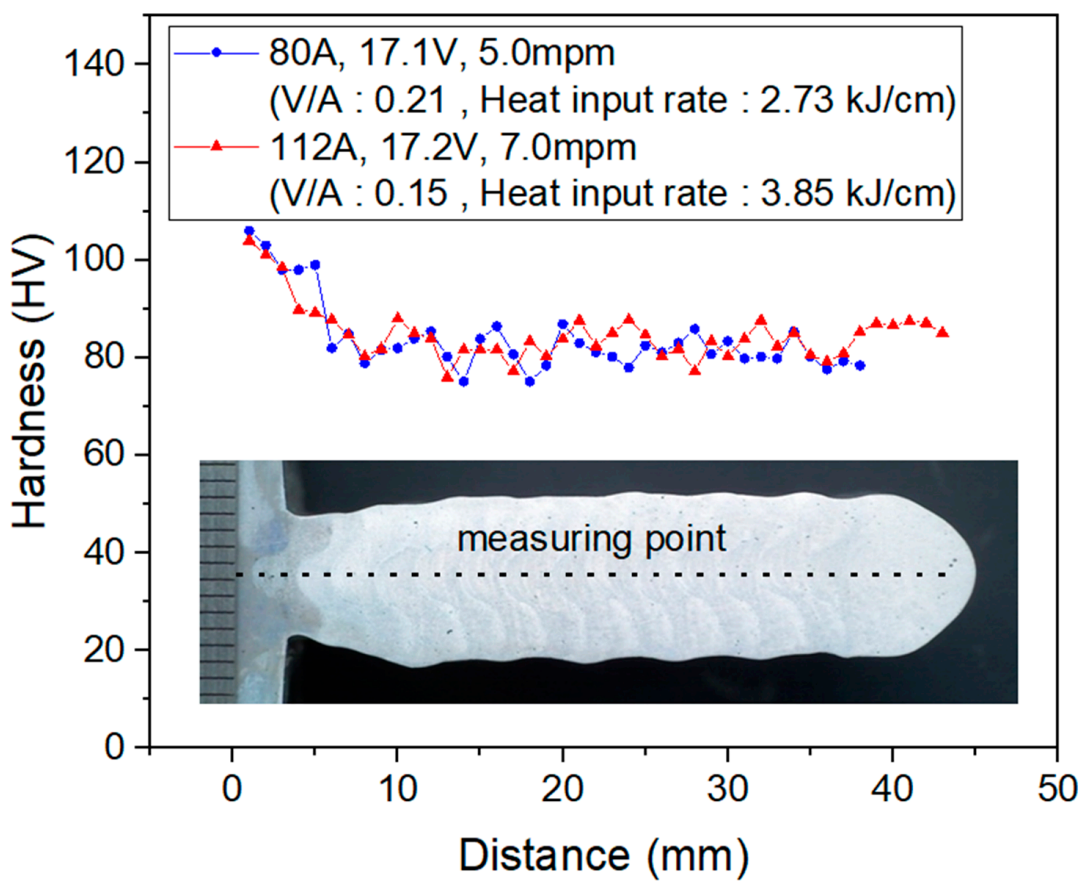

Figure 12. Hardness comparison by the difference between the current and voltage ratio and heat input rate. 


\section{Conclusions}

This study fabricated a single bead and thin-wall parts by depositing aluminum alloys with wire arc additive manufacturing (WAAM) technology, analyzed the cross-sectional geometry of the bead and confirmed the following:

1. Using nine welding conditions, the change in bead geometry caused by the heat input and current and voltage ratio was quantitatively analyzed. The heat input range in the test was from about $2.7 \mathrm{~kJ} / \mathrm{cm}$ to $4.5 \mathrm{~kJ} / \mathrm{cm}$, and the higher the heat input, the higher the deposition efficiency. This study confirmed that the maximum deposition efficiency is $76 \%$.

2. A single bead directly affects the efficiency of the thin-wall parts during continuous deposition. To increase the deposition efficiency, the bead height, contact angle and bead diameter must be large or high, and the position of the bead center must be close to the base material surface. For this, a high heat input must be used.

3. This study quantified the voltage portion in the total heat input by using the current and voltage ratio and analyzed its effects on the bead geometry. When the portion of the voltage for weld settings with similar heat inputs decreased by about $10 \%$, it was found that the deposition efficiency decreased by $1 \%$ to $3 \%$. To increase the deposition efficiency, it is necessary to increase the portion of the voltage in the total heat input to ensure that sufficient heat is supplied to the base material and wire.

4. As a result of performing a hardness test instead of a tensile strength evaluation, the difference in the hardness value of the layer portion did not occur due to the difference between the current and voltage ratio and the heat input rate, and was measured as $80 \mathrm{HV}$ on average.

Author Contributions: Conceptualization, J.K. (Jisun Kim), J.K. (Jaewoong Kim), H.-k.L., and C.P.; experiment, H.-k.L. and J.K. (Jisun Kim); software, C.P.; validation, C.P., J.K. (Jaewoong Kim) and J.K. (Jisun Kim); paper research, C.P., J.K. (Jaewoong Kim) and J.K. (Jisun Kim); Data analysis, J.K. (Jisun Kim), H.-k.L. and J.K. (Jaewoong Kim); writing—original draft preparation, J.K. (Jisun Kim); writing—review and editing, J.K. (Jisun Kim), H.-k.L. and C.P.; supervision, J.K. (Jisun Kim) and J.K. (Jaewoong Kim); project administration, J.K. (Jaewoong Kim). All authors have read and agreed to the published version of the manuscript.

Funding: This study has been conducted with the support of the Korea Institute of Industrial Technology as "Development of Core Technologies for a Smart Mobility (PJA20073)".

Conflicts of Interest: The authors declare no conflict of interest.

\section{References}

1. Megan, R.N. How does the automotive industry benefit from 3D metal printing? Met. Powder Rep. 2019, 74, 257-258. [CrossRef]

2. Shahrubudin, N.; Lee, T.C.; Ramlan, R. An Overview on 3D Printing Technology: Technological, Materials and Applications. Procedia Manuf. 2019, 35, 1286-1296. [CrossRef]

3. Brookes, K.J.A. 3D printing materials in Maastricht. Met. Powder Rep. 2015, 70, 68-78. [CrossRef]

4. Samit, C.; Manik, C.B. 3D printing technology of polymer-fiber composites in textile and fashion industry: A potential roadmap of concept to consumer. Compos. Struct. 2020, 248, 112562. [CrossRef]

5. Lim, C.H.; Srithar, R.; Alias, M.N.; Norhayati, A.; Uday, M.B. Recent advances in 3D printing of porous ceramics: A review. Curr. Opin. Solid State Mater. Sci. 2017, 21, 323-347. [CrossRef]

6. Lee, J.Y.; An, J.; Chua, C.K. Fundamentals and applications of 3D printing for novel materials. Appl. Mater. Today 2017, 7, 120-133. [CrossRef]

7. Chua, C.K.; Leong, K.F. 3D Printing and Additive Manufacturing: Principles and Applications, 5th ed.; World Scientific Publishing Company: Singapore, 2017; Available online: https: //books.google.co.kr/books?hl=ko\&lr=\&id=Gy88DQAAQBAJ\&oi=fnd\&pg=PR7\&ots=kh7zSlFWh1\&sig= HF84hBkXZYhGIzHbV3m_uAI53QU\&redir_esc=y\#v=onepage\&q\&f=false (accessed on 18 March 2017).

8. Karakurt, I.; Lin, L. 3D printing technologies: Techniques, materials and post-processing. Curr. Opin. Chem. Eng. 2020, 28, 134-143. [CrossRef] 
9. Cunningham, C.R.; Flynn, J.M.; Shokrani, A.; Dhokia, V.; Newman, S.T. Invited review article: Strategies and processes for high quality wire arc additive manufacturing. Addit. Manuf. 2018, 22, 672-686. [CrossRef]

10. Wu, B.; Pan, Z.; Ding, D.; Cuiuri, D.; Li, H.; Xu, J.; John, N. A review of the wire arc additive manufacturing of metals: Properties, defects and quality improvement. J. Manuf. Process. 2018, 35, 127-139. [CrossRef]

11. Patrycja, S.Z.; Magdalena, B.Ł.; Jerzy, D.; Izabela, M.; Piotr, G. A review of fabrication polymer scaffolds for biomedical applications using additive manufacturing techniques. Biocybern. Biomed. Eng. 2020, 40, 624-638. [CrossRef]

12. Prado-Cerqueira, J.L.; Diéguez, J.L.; Camacho, A.M. Preliminary development of a Wire and Arc Additive Manufacturing system (WAAM). Procedia Manuf. 2017, 13, 895-902. [CrossRef]

13. Oliveira, J.P.; Santos, T.G.; Miranda, R.M. Revisiting fundamental welding concepts to improve additive manufacturing: From theory to practice. Prog. Mater. Sci. 2020, 107, 100590. [CrossRef]

14. Lee, T.H.; Kang, M.; Oh, J.H.; Kam, D.H. Parametric study of STS316L Deposition with Arc and Wire additive Manufacturing. J. Weld. Join. Soc. 2018, 36, 23-30. [CrossRef]

15. Kam, D.H.; Kim, Y.M.; Kim, C. Recent Studies of Laser Metal 3D Deposition with Wire Feeding. J. Weld. Join. Soc. 2016, 34, 35-40. [CrossRef]

16. Amit, B.; Bryan, H. Additive manufacturing of multi-material structures. Mater. Sci. Eng. R: Rep. 2018, 129, 1-16. [CrossRef]

17. Martina, F.; Mehnen, J.; Williams, S.W.; Colegrove, P.; Wang, F. Investigation of the benefits of plasma deposition for the additive layer manufacture of Ti-6Al-4V. J. Mater. Process. Technol. 2012, 212, 1377-1386. [CrossRef]

18. Köhler, M.; Hensel, J.; Dilger, K. Effects of Thermal Cycling on Wire and Arc Additive Manufacturing of Al-5356 Components. Metals 2020, 10, 952. [CrossRef]

19. Fang, X.; Zhang, L.; Chen, G.; Dang, X.; Huang, K.; Wang, L.; Lu, B. Correlations between Microstructure Characteristics and Mechanical Properties in 5183 Aluminium Alloy Fabricated by Wire-Arc Additive Manufacturing with Different Arc Modes. Materials 2018, 11, 2075. [CrossRef]

20. Xiong, J.; Zhang, G.; Gao, H.; Wu, L. Modeling of bead section profile and overlapping beads with experimental validation for robotic GMAW-based rapid manufacturing. Robot Cim.-Int. Manuf. 2013, 29, 417-423. [CrossRef]

21. Xiong, J.; Zhang, G. Adaptive control of deposited height in GMAW-based layer additive manufacturing. J. Mater. Process. Technol. 2014, 214, 962-968. [CrossRef]

22. Ola, O.T.; Doern, F.E. A study of cold metal transfer clads in nickel-base INCONEL 718 superalloy. Mater. Des. 2014, 57, 51-59. [CrossRef]

23. Kim, S.; Lim, S. Repair Properties of Desulfurization Pump Part Layers by Direct Energy Deposited Additive Manufacturing Process. J. Weld. Join. Soc. 2020, 38, 92-97. [CrossRef]

24. Choi, S.W.; Hong, J.; Park, C.H. Manufacturing Process of Titanium Alloys Flux-Metal Cored Wire for Gas Tungsten Arc Welding. J. Weld. Join. Soc. 2019, 37, 268-274. [CrossRef]

25. Byun, J.G.; Cho, S.M. Trend of Metal 3D Printing by Welding. J. Weld. Join. Soc. 2016, 34, 1-8. [CrossRef]

(C) 2020 by the authors. Licensee MDPI, Basel, Switzerland. This article is an open access article distributed under the terms and conditions of the Creative Commons Attribution (CC BY) license (http://creativecommons.org/licenses/by/4.0/). 